\title{
Alteración del colágeno en la Hipertrofia Gingival en pacientes con ortodoncia: caracterización histológica e inmunohistoquímica
}

\section{Collagen alteration in gingival hypertrophy in orthodontic patients: histological and immunohistochemical characterization}

\author{
Víctor Simancas-Escorcia $^{1}{ }^{\mathbb{D}}$; Ariana Lozada-Martínez $^{1}{ }^{\mathbb{D}}$; Antonio Díaz-Caballero $^{1}{ }^{(\mathbb{D})}$
}

Forma de citar: Simancas-Escorcia V, Lozada Martínez A, Díaz Caballero A. Alteración del colágeno en la Hipertrofia gingival en pacientes con ortodoncia e inmunohistoquímica. Salud UIS. 53: e21007. doi: https://doi.org/10.18273/saluduis.53.e:21007 (c) (1)

\section{Resumen}

Introducción: la hipertrofia gingival (HG) es el aumento del volumen de la encía asociado a ciertas enfermedades sistémicas, hereditarias (idiopático), ingesta de algunos medicamentos o a factores locales como el tratamiento ortodóntico, capaz de provocar cambios histológicos en el tejido conectivo gingival. Objetivo: describir las características histológicas e identificar el colágeno tipo I y tipo III en tejidos gingivales de sujetos con hipertrofia gingival portadores de ortodoncia. Materiales y método: Se diseñó un estudio de casos y controles que incluyó el análisis de biopsias de tejido gingival de 12 pacientes sometidos a cirugías periodontales. La muestra se dividió en dos grupos: individuos sanos (control; $n=6$ ) y pacientes con HG portadores de ortodoncia (pacientes; $n=6$ ). Las muestras fueron procesadas e incluidas en parafina. Las tinciones Masson-Goldner y rojo sirius/verde rápido fueron empleadas. El colágeno tipo I y tipo III fueron identificados mediante inmunohistoquímica con anticuerpos monoclonales. Resultado: en los pacientes con HG portadores de ortodoncia se observó un epitelio hiperplásico y tejido conectivo denso con abundantes fibras de colágeno distribuidos aleatoriamente. La inmunodetención de colágeno tipo I indicó la presencia de abundantes fibras desorganizadas y el colágeno tipo III fue inmunolocalizado subyacente a la membrana basal, vasos sanguíneos y toda la extensión del tejido conectivo de los pacientes con HG con tratamiento ortodóntico. Conclusión: la acumulación de fibras de colágeno, particularmente del colágeno tipo I y tipo III, son hallazgos histológicos que caracterizan la HG en pacientes portadores de ortodoncia. Futuros estudios son necesarios para dilucidar el fenotipo de los fibroblastos gingivales y la probable pérdida homeostática entre la producción y degradación de colágeno en esta patología.

Palabras clave: Hipertrofia Gingival; Ortodoncia; Encía; Colágeno Tipo I; Colágeno Tipo III; Fibroblastos; Aparatos Ortodónticos.

1. Universidad de Cartagena. Bolivar, Colombia.

Correspondencia: Víctor Simancas-Escorcia. Dirección: Av. Calle 30 48-152 Barrio Zaragocilla. Universidad de Cartagena. Teléfono:

+5 6698172. Correo electrónico: vsimancasescorcia@hotmail.com 


\begin{abstract}
Introduction: Gingival hypertrophy $(\mathrm{GH})$ is the increase in the volume of the gingiva associated with certain systemic, hereditary (idiopathic) diseases, the intake of some medications or local factors such as orthodontic treatment, capable of causing histological changes in the gingival connective tissue. Objective: To describe the histological characteristics and identify type I and type III collagen in gingival tissues of subjects with gingival hypertrophy wearing orthodontics. Method: A case-control study was designed that included the analysis of gingival tissue biopsies from 12 patients submitted to periodontal surgeries. The sample was divided into two groups: healthy individuals (Control; $n=6$ ) and patients with GH wearing orthodontics (Patients; $n=6$ ). The samples were processed and embedded in paraffin. Masson-goldner and sirius red/fast green stains were used. Type I and type III collagen were identified by immunohistochemistry with monoclonal antibodies. Result: A hyperplastic epithelium and dense connective tissue with abundant randomly distributed collagen fibers were observed in patients with orthodontic $\mathrm{GH}$. Immunodetention of type I collagen indicated the presence of abundant disorganized fibers and type III collagen was inmunolocalized underlying the basement membrane, blood vessels and the entire extension of the connective tissue of patients with GH orthodontic. Conclusion: The accumulation of collagen fibers, particularly type I and type III collagen, are histological findings that characterize GH in orthodontic wearers. Future studies are necessary to elucidate the phenotype of gingival fibroblasts and the probable homeostatic loss between collagen production and degradation in this pathology.
\end{abstract}

Keywords: Gingival Hypertrophy; Orthodontic; Gingiva; Collagen Type I; Collagen Type III; Fibroblasts; Orthodontic Appliances.

\section{Introducción}

La hipertrofia gingival (HG) es el aumento o engrosamiento del volumen de los tejidos blandos que cubren la cresta alveolar ${ }^{1}$. Esta condición patológica inicia generalmente en la encía interdental, presenta una forma lobular y en estadios más avanzados puede afectar toda la encía ${ }^{2}$. La severidad de la HG genera dificultades en la masticación, alteraciones en la fonación, problemas estéticos y la creación de zonas de difícil acceso para la remoción mecánica de biofilm ${ }^{3}$. La HG está relacionada con factores sistémicos y locales. Dentro de los factores sistémicos se destacan las discrasias sanguíneas severas (leucemias), hereditarias (idiopático $)^{4}$, procesos patológicos como el síndrome esmalte renal ${ }^{5,6}$, la ingesta prolongada de algunos medicamentos e incluso al desequilibrio hormonal durante el embarazo ${ }^{7,8}$. Como factores locales más comunes relacionados con la HG se encuentran las restauraciones desadaptadas, aparatología removible y tratamientos de ortodoncia ${ }^{1}$.

El tratamiento de ortodoncia tiene como propósito obtener una armonización dental basada en una oclusión con criterios fisiológicos y estéticos a partir de movimientos dentales. Estos movimientos están estrechamente relacionados con los tejidos periodontales de soporte. En los últimos años, probablemente por un aumento en el número de sujetos portadores de tratamiento ortodóntico, los ortodoncistas, periodoncistas y odontólogos generales frecuentemente deben enfrentarse a pacientes con problemas periodontales, incluyendo la aparición de eventos patológicos adversos como el agrandamiento gingival o hipertrofia gingival'. En poblaciones estudiadas con tratamiento ortodóntico, la prevalencia de la HG oscila alrededor del $50 \%{ }^{10}$.

Por su parte, la patogénesis de la $\mathrm{HG}$ en pacientes con ortodoncia no es clara, pero se ha indicado que diversos factores pueden inducir esta patología. Entre ellos, la irritación mecánica por bandas, irritación química producida por los materiales usados para la adhesión o bien, como respuesta inflamatoria a la acumulación de la biopelícula y su difícil remoción. También se ha sugerido que las dosis bajas de níquel liberadas hacia el epitelio pueden ser un factor desencadenante de la $\mathrm{HG}^{9}$. Algunos estudios indican que los cambios gingivales durante el tratamiento de ortodoncia no generan una agresión permanente en los tejidos periodontales. Sin embargo, otras investigaciones reportan que los efectos de la inflamación del tejido gingival y las fuerzas ejercidas durante el tratamiento ortodóntico pueden incluso generar un descubrimiento radicular de los dientes ${ }^{11}$.

En general, a nivel histológico los tejidos de pacientes con $\mathrm{HG}$ presentan un tejido conectivo rico en fibras de colágeno. Se ha sugerido que la HG puede presentar un aumento de tamaño de la lámina propia debido a la acumulación de fibras de colágeno y la presencia de una actividad proliferativa aumentada por parte de 
los fibroblastos gingivales (FGs), mientras que otros estudios describen la expansión del tejido conectivo como resultado de la acumulación de matriz extracelular (MEC) rica en colágeno sin asociación directa con el número de $\mathrm{FGs}^{12,13}$. Sin embargo, en ambos casos el depósito de colágeno tisular es evidente. En los pacientes con HG portadores de ortodoncia, los aspectos generales del colágeno tisular y la presencia del colágeno tipo I y tipo III han sido escasamente investigados. Por lo anterior, el objetivo de este estudio fue describir las características histológicas e identificar el colágeno tipo I y tipo III en tejidos gingivales de sujetos con hipertrofia gingival portadores de ortodoncia.

\section{Materiales y métodos}

Se diseñó un estudio de casos y controles que incluyeron 12 pacientes. Un primer grupo estuvo integrado por sujetos periodontalmente sanos (encía rosada en ausencia de sangrado), no portadores de tratamiento de ortodoncia y con requerimientos de alargamiento coronal por razones protésicas o estéticas (control; $\mathrm{n}=6$ ). En el segundo grupo fueron incluidos los pacientes con diagnóstico de hipertrofia gingival generalizada asociada a tratamiento ortodóntico en curso ( $\geq 1$ año), localizada en la encía marginal e interdental sin exceder $1 / 3$ de la corona clínica (pacientes; $n=6$ ), de acuerdo a los parámetros establecidos en el trabajo de Pinto, et al. ${ }^{11}$. Las intervenciones clínicas fueron desarrolladas por el equipo de periodoncistas adscritos al Centro de Referencia de Hipertrofia Gingival de la Facultad de Odontología de la Universidad de Cartagena.

Se admitieron sujetos mayores de 18 años, con buen estado de salud sistémica que no se hallaban bajo tratamiento farmacológico. Se excluyeron aquellos individuos con antecedentes de cirugía periodontal menor a un año, pacientes con procesos inflamatorios activos en el periodonto o evidencia radiográfica de pérdida ósea, así como fumadores y embarazadas. A cada sujeto se le disminuyó la carga bacteriana con eliminación ultrasónica y manual de cálculos y biopelícula dental antes de cada procedimiento quirúrgico, garantizando la presencia de un índice de placa O'Leary $\leq 15 \%$.

\section{Preparación de muestras}

El grupo control y de pacientes con HG portadores de ortodoncia fueron sometidos a un alargamiento coronal y gingivectomía, respectivamente. Ambas intervenciones quirúrgicas fueron efectuadas bajo anestesia infiltrativa con Lidocaína $2 \%$ y epinefrina
1:80000 en el área quirúrgica. Se realizó una incisión a bisel externo e intrasulcular con bisturí Bard Parker número 15. Se evitó el uso de bisturí eléctrico para minimizar factores de variabilidad. A los 7 días, una evaluación postquirúrgica permitió constatar una adecuada cicatrización tisular en todos los pacientes, sin complicaciones.

Una vez recuperados los tejidos, estos fueron depositados en tubos Eppendorf, lavados en solución salina tamponada con fosfato (PBS 1X, Gibco ${ }^{\mathrm{TM}}$ ) y cortadas en segmentos de 4-6 $\mathrm{mm}^{3}$ para luego sumergirlas en paraformaldehído 4\% tamponado durante 48 horas. Las biopsias fueron incluidas en etanol $(30 \%, 60 \%, 80 \%, 95 \%, 100 \%)$ durante 5 minutos cada una, seguidas de baños de xileno (Leica Biosystems) para su deshidratación e incluidas en parafina. Una vez obtenido cada bloque, se llevaron a cabo cortes seriados de $5 \mu \mathrm{m}$ en un micrótomo Leica RM2125 RST. Estos cortes fueron depositados en portaobjetos de adhesión con polisina (Thermo Scientific ${ }^{\mathrm{TM}}$ ). Finalmente, se seleccionaron cuatro láminas consecutivas de cada paciente para proceder a la tinción de MassonGoldner, tinción rojo sirius/verde rápido y la detención inmunohistoquímica del colágeno tipo I y tipo III.

\section{Coloración de Masson-Goldner}

Los cortes de tejido gingival depositados en portaobjetos fueron sumergidos en baños de xileno (Leica Biosystems) y rehidratados en concentraciones decrecientes de alcohol (100\%, 95\%, 80\%, 60\%, $30 \%$ ) durante 5 minutos en cada uno. Posteriormente, los cortes fueron coloreados durante 20 minutos en hematoxilina de Mayer, seguida de una diferenciación acido-alcohol por 30 segundos. Después, los cortes estuvieron en contacto con tres soluciones: solución de azofloxina (10 minutos, Sigma-Aldrich), solución de ácido fosfovolfrámico-anaranjado G (1 minuto, SigmaAldrich) y verde luz (2 minutos, Sigma-Aldrich) con un enjuague en agua destilada después de cada tinción. En último lugar, se procedió al montaje de las láminas con un medio de montaje anhidro (DPX, Sigma-Aldrich). Mediante esta coloración, las fibras de colágeno se tiñeron de verde, los núcleos celulares en violeta oscuro y citoplasma en rojo ladrillo.

\section{Coloración rojo picrosirius/verde rápido}

Luego de desparafinar y rehidratar los cortes en alcohol, estos fueron coloreados con verde rápido a $0,03 \%$ (Sigma-Aldrich) durante 20 minutos y lavados en agua 
destilada por 5 minutos. A continuación, se llevó a cabo una coloración con rojo sirius a 0,1\% (Sigma-Aldrich) durante 5 minutos y un enjuague en agua destilada. Finalmente, los cortes fueron deshidratados, lavados en xileno y montados en DPX (Sigma-Aldrich). Las fibras de colágeno se colorearon de rojo y el citoplasma de células en amarillo.

\section{Inmunohistoquímica}

Una vez las secciones de tejidos fueron desparafinadas en xileno y etanol, se procedió a la recuperación antigénica mediante la incubación en un tampón de citrato pH6 durante 20 minutos a $97^{\circ} \mathrm{C}$. Para el bloqueo de la peroxidasa endógena se utilizó una solución peróxido de hidrogeno al 3\% durante 15 minutos. Luego de ser lavados (solución salina tamponada con Tris (TBS 1X, Gibco $\left.^{\mathrm{TM}}\right)+$ monolaurato de polioxietilen (20 sorbitano o Tween ${ }^{\circledR} 20$ a $0,05 \%$ )) (3x5 minutos), se realizó el bloqueo de los sitios específicos con suero normal de caballo (Vector Laboratories) durante 20 minutos. Después, los cortes se incubaron con los anticuerpos primarios anti-Colágeno de tipo I (Mouse monoclonal antibody Type I, dilución 1:500, clone COL-1, SigmaAldrich) y anti-Colágeno tipo III (Mouse monoclonal antibody Type III, dilución 1:500, clone FH-7A, Sigma-Aldrich) durante toda la noche a $4{ }^{\circ} \mathrm{C}$. Al día siguiente, previo lavado, los cortes se incubaron en el anticuerpo secundario biotinilado anti-mouse (Vector Laboratories) y con el sistema de peroxidasa R.T.U VECTATASTAIL ${ }^{\circledR}$ ABC (Vector Laboratories) por 30 minutos cada uno a temperatura ambiente. La reacción se visualizó con una solución de sustrato de peroxidasa durante 4 minutos. La reacción fue detenida mediante lavados sucesivos con agua destilada. Por último, los tejidos fueron contra-coloreados con hematoxilina de Mayer durante 30 segundos, deshidratados en etanol, seguido de xileno y montados con DPX. Las reacciones del colágeno tipo I y tipo III fueron consideradas positivas al observar un marcaje color marrón en la matriz extracelular (MEC). Todas las observaciones se realizaron en un microscopio óptico Leica DM 500 conectado a una cámara fotográfica.

\section{Resultados}

Del total de pacientes evaluados en este trabajo, el $60 \%$ (6) fueron del sexo femenino. El promedio de edad fue de 22,8 años en el grupo control y 20,8 años en el grupo de pacientes con HG portadores de ortodoncia. Las muestras tisulares de sujetos sanos examinados mediante la coloración Masson-Goldner permitió constatar un epitelio gingival compuesto de una capa de queratina y células con núcleos redondos u ovalados sin signos aparentes de cambios y/o alteraciones que integraban las capa granulosa, espinosa y basal de este tejido. Se observaron prolongaciones epiteliales bien delimitadas que se incluían hacía el tejido conectivo subyacente (Figura 1A). En la matriz extracelular de los individuos sanos fueron identificados fibroblastos gingivales como elementos celulares predominantes, localizados principalmente entre los haces de las fibras de colágeno. Este colágeno era organizado y se observó en toda la extensión del tejido conectivo. Fueron igualmente observados vasos sanguíneos de diferentes diámetros (Figura 1 A-C). En contraste, las muestras provenientes de pacientes con $\mathrm{HG}$ portadores de ortodoncia permitieron identificar una acantosis e hiperplasia del epitelio. Se apreció un aumento no cuantificable en el volumen de las crestas epiteliales, muchas de ellas fusionadas entre sí. La parte superficial de la lámina propia y su papila evidenciaban abundantes vasos sanguíneos (Figura 1D). Las fibras de colágeno tuvieron un aspecto estructural compacto con pocos espacio interfibrilares y dispuestas aleatoriamente en todo el tejido conectivo gingival. La abundante red de colágeno también fue identificada alrededor de los vasos sanguíneos (Figura 1E, F).

En los individuos sanos, la tinción rojo picrosirius/ verde rápido reveló la presencia de fibras de colágeno organizadas en paquetes, muchas de ellas, en largos haces que recorrían todo el tejido conectivo. Se apreció también la presencia de vasos sanguíneos en todo el tejido (Figura $2 \mathrm{~A}-\mathrm{C}$ ). En los pacientes con tratamiento ortodóntico diagnosticados con $\mathrm{HG}$, se evidenció, además, el engrosamiento del epitelio, así como prolongaciones epiteliales de gran tamaño. La lámina propia en las secciones examinadas consistió en densos haces de fibras de colágeno cerca de los vasos sanguíneos, muchos de ellos con aparente forma dilatada (Figura 2 D-I).

El análisis inmunohistoquímico realizado para la detección de colágeno tipo I fue positiva en todas las muestras de los individuos sanos. Así mismo, se pudo apreciar un número no cuantificable de fibroblastos gingivales sin aparentes signos de alteraciones en su aspecto morfológico (Figura 3 A-B). En las muestras de tejido con $\mathrm{HG}$ de pacientes con ortodoncia, se presentan gruesos haces de fibras de colágeno tipo I positivas y un aparente aumento visual en la expresión de este colágeno en comparación con los tejidos gingivales de individuos sanos (Figura 3 C-D). 

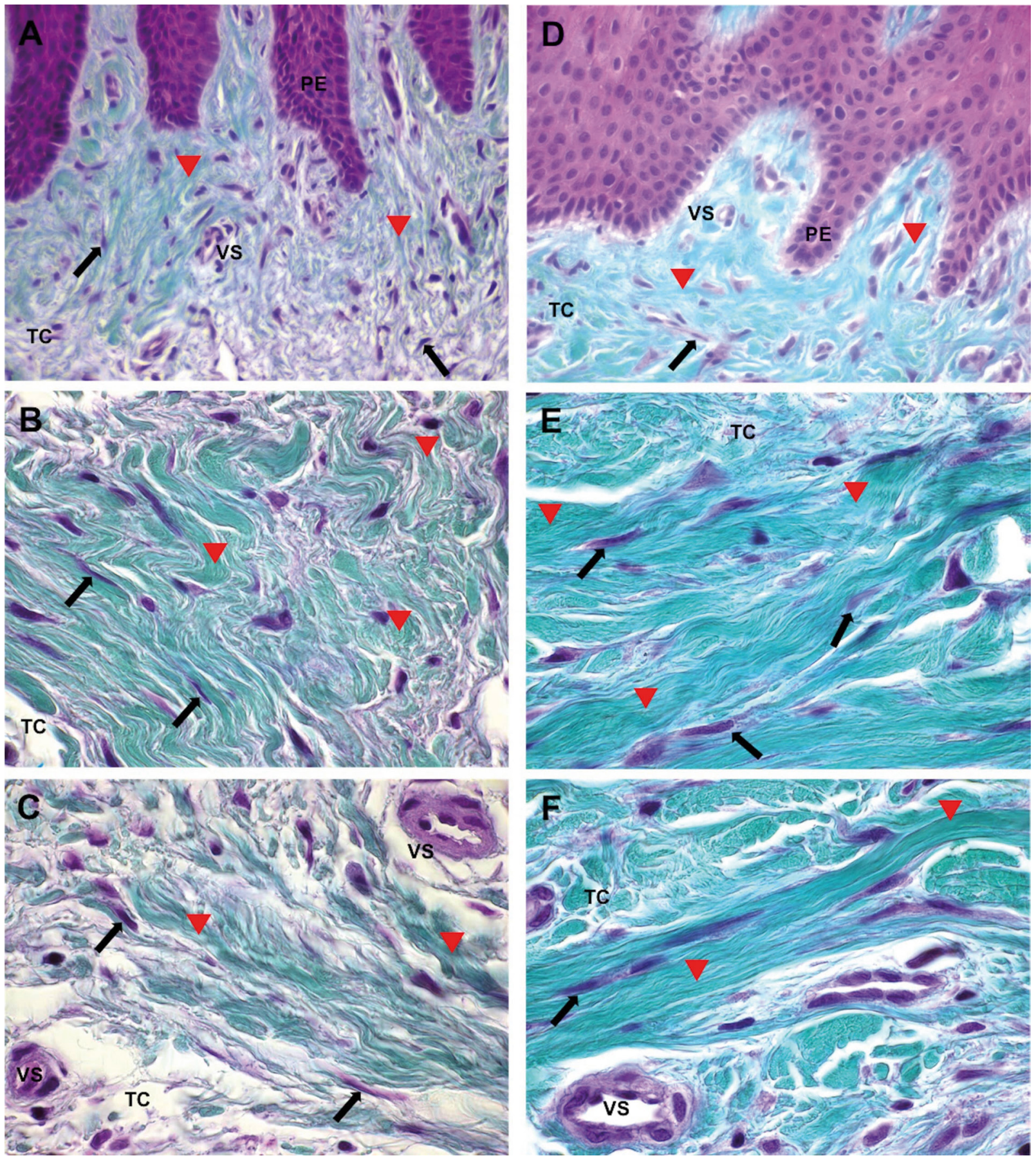

Figura 1. Visualización del tejido gingival en individuo sano y paciente con ortodoncia diagnosticado con hipertrofia gingival (HG). (A,B,C). Fibras de colágeno (triangulo rojo) distribuidas en la lámina basal y extensión del tejido conectivo de sujeto sano. Se aprecian fibroblastos gingivales (flechas negras) y vasos sanguíneos (VS). (D,E,F) Abundante presencia de fibras colágeno en lámina basal y zona subyacente de los tejidos de paciente con HG portador de ortodoncia. Nótese la red compacta de fibras de colágeno, fibroblastos gingivales y vasos sanguíneos. Coloración Masson-Goldner. TE: tejido epitelial; PE: prolongaciones epiteliales; TC: tejido conectivo. 40x (A,D), 100x (B,C,E,F). Fuente: elaboración propia. 

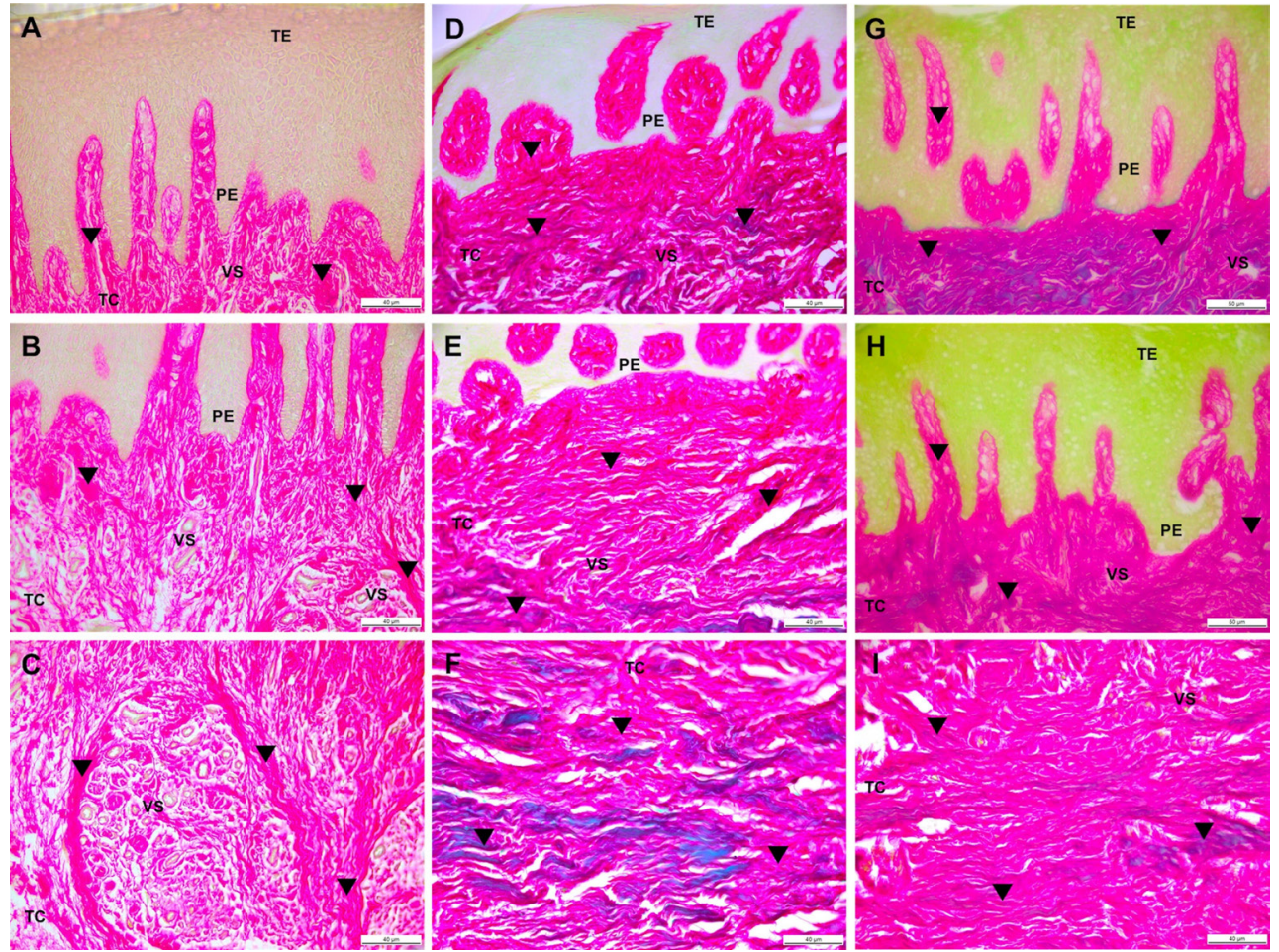

Figura 2. Secciones fotográficas de tejido gingival coloreado con rojo picrosirius/verde rápido. (A, B, C). Fibras de colágeno (triangulo negro) en individuo sano. (D-I) Tejido con hipertrofia gingival de paciente con ortodoncia muestra densos haces de colágeno en todo el tejido conectivo (TC) y múltiples vasos sanguíneos (VS). TE: tejido epitelial; PE: prolongaciones epiteliales. Barra negra: $40 \mu \mathrm{m}(\mathrm{A}-\mathrm{F}, \mathrm{I}), 50 \mu \mathrm{m}(\mathrm{G}, \mathrm{H})$. Fuente: elaboración propia.
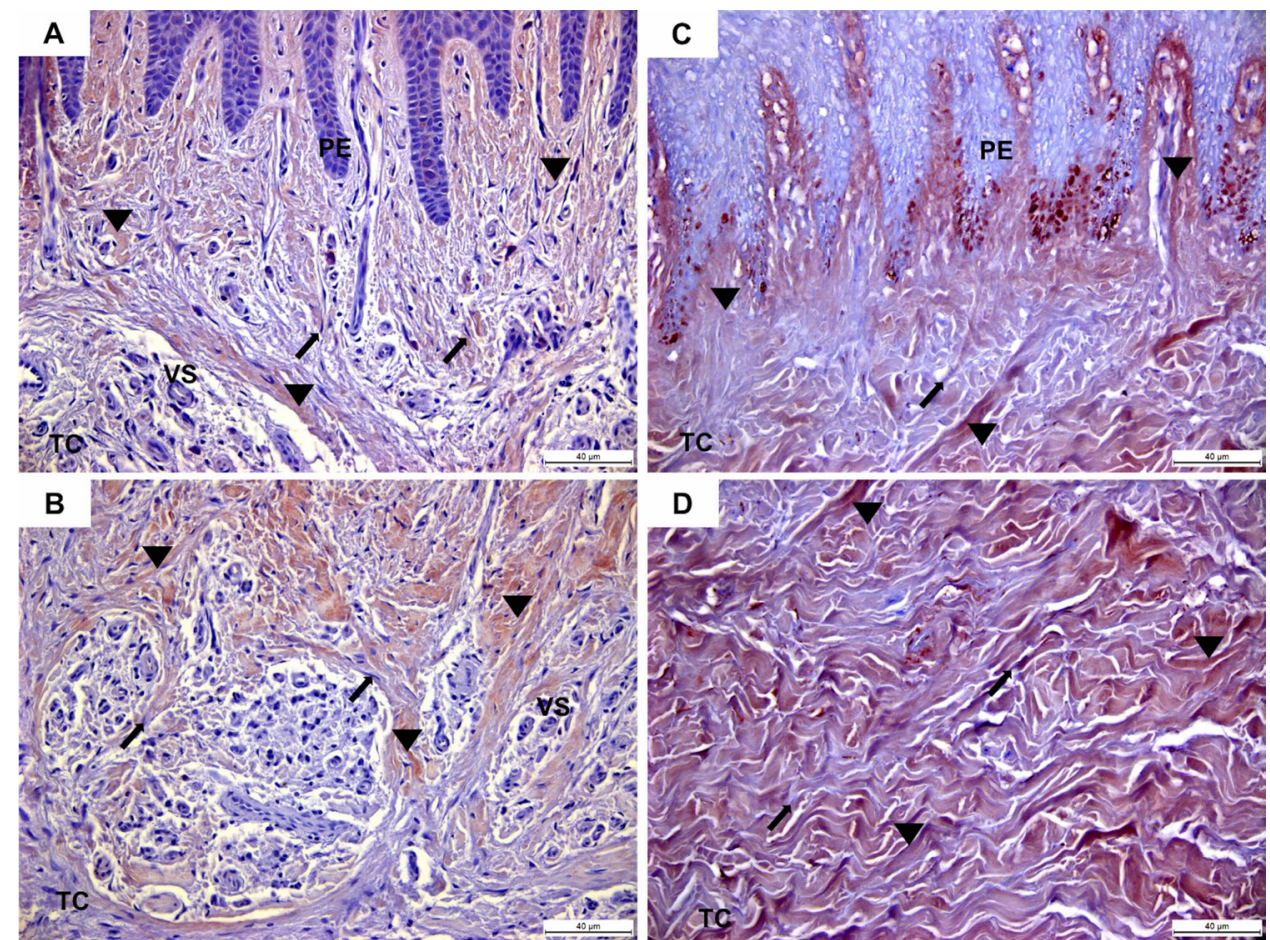

Figura 3. Análisis inmunohistoquímico de colágeno tipo I. (A, B) Colágeno tipo I (triangulo negro) y fibroblastos gingivales (flechas negras) en tejido gingival de individuo sano (C, D). Paciente con hipertrofia gingival portador de ortodoncia donde se aprecian gruesos haces de fibras de colágeno en toda la extensión del tejido conectivo. PE: prolongaciones epiteliales; TC: tejido conectivo; VS: vasos sanguíneos; Barra negra: $40 \mu \mathrm{m}$ (A-D). Colágeno tipo I: en color marrón. Fuente: elaboración propia. 
En las secciones del tejido gingival proveniente de sujetos sanos analizados con la inmunolocalización del colágeno tipo III se evidenció un leve marcaje en el tejido conectivo. Este fue localizado en la proximidad de la membrana basal donde delgados haces de fibras de colágeno fueron observadas (Figura 4 A-B). En las muestras de los pacientes con HG portadores de ortodoncia, la presencia de gruesas redes de colágeno tipo III fueron notoriamente más abundantes en comparación con los tejidos de individuos sanos. Las fibras de colágeno tipo III identificada en los pacientes con HG fueron largas y se distribuían en diferentes orientaciones en todo el tejido conectivo, incluyendo las zonas adyacentes de los vasos sanguíneos (Figura 4 C-D).
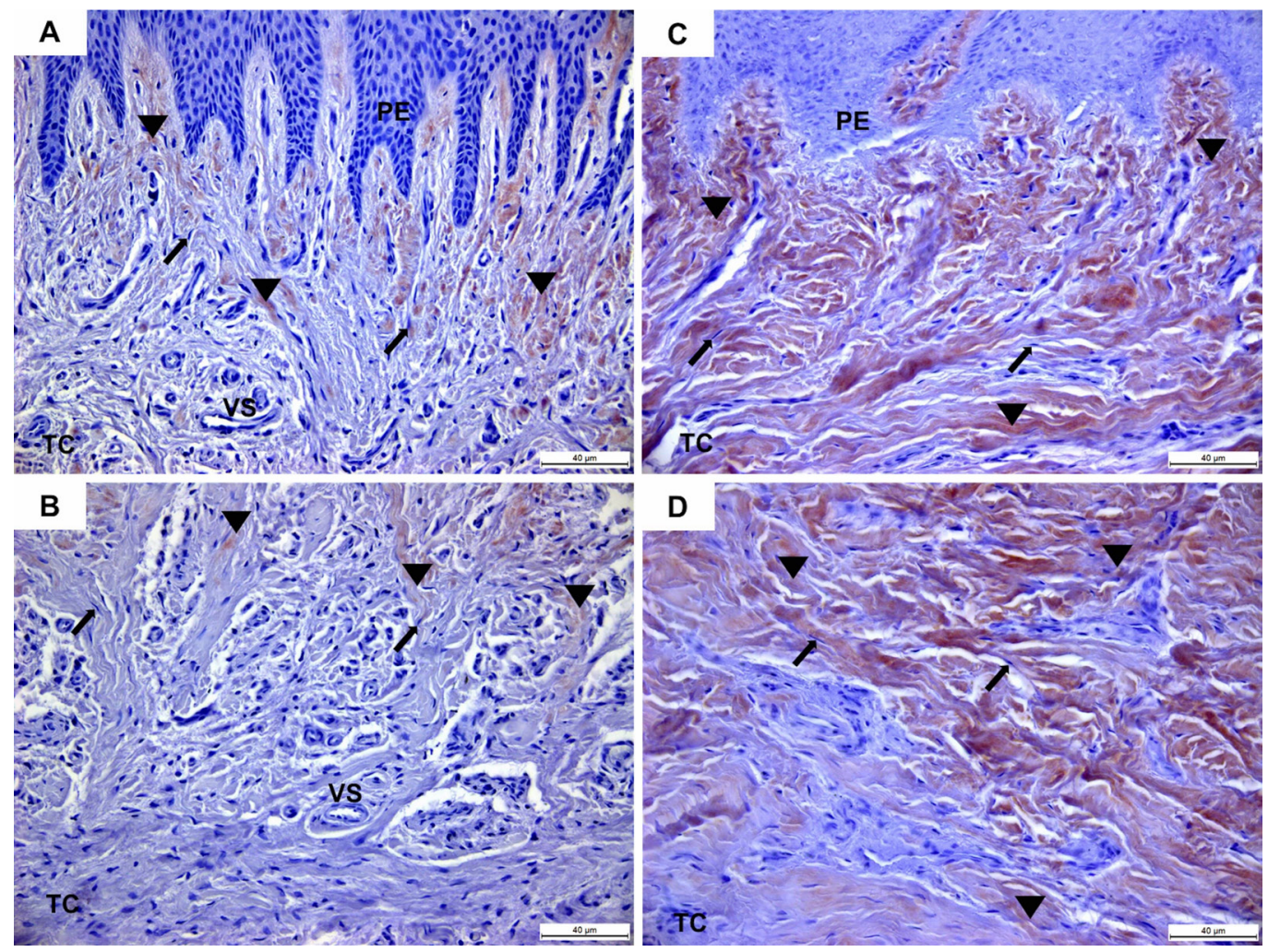

Figura 4: Inmunodetención de colágeno tipo III. (A, B) Tejido gingival de sujeto sano con presencia de colágeno tipo III en zona sub-epitelial. (C, D) Abundante presencia de fibras de colágeno de tipo III en pacientes con hipertrofia gingival portador de tratamiento de ortodoncia. PE: prolongaciones epiteliales; TC: tejido conectivo; VS: vasos sanguíneos; Barra negra: $40 \mu \mathrm{m}$ (A-D). Colágeno tipo III: en color marrón. Fuente: elaboración propia.

\section{Discusión}

En este estudio informamos las características histológicas de las fibras de colágeno e inmunohistoquímica del colágeno tipo I y tipo III en muestras de encías de pacientes diagnosticados con HG portadores de tratamiento ortodóntico e individuos sanos. El análisis histológico de todas las muestras de sujetos con HG indicó la presencia de un tejido epitelial engrosado con prolongaciones epiteliales alargadas de gran tamaño dispuestas en un tejido conectivo fibroso. Así mismo, los resultados presentados aquí ponen en evidencia que los haces de las fibras de colágeno también se hallaban aumentados y sorprendentemente abundantes en todo el tejido conectivo de los pacientes con HG que usaban ortodoncia. Estos hallazgos señalan que el agrandamiento gingival presente en estos pacientes incluye una respuesta de proliferación epitelial aumentada, respaldada por el aumento de los haces de las fibras de colágeno. Estos resultados son compatibles con los reportados por Pascu, et al. ${ }^{1}$ donde fueron comparadas las características histológicas de lesiones fibróticas causadas por diferentes factores etiológicos, observando que en los pacientes con HG portadores de ortodoncia se presentó engrosamiento del epitelio, aumento en la queratinización de las capas superficiales y abundante presencia de fibras de colágeno. 
El análisis histológico en los pacientes con HG portadores de ortodoncia presentado aquí difiere del agrandamiento gingival inflamatorio asociado por la acumulación de biofilm bacteriano alrededor de los dispositivos ortodónticos previamente descritos por Jadhav, et al. ${ }^{14}$. Aunque en el presente trabajo fueron identificadas de manera aislada células inflamatorias en los pacientes con $\mathrm{HG}$, este hallazgo no fue compatible con exudado o un predominio absoluto de células inflamatorias en los tejidos de estos pacientes. De hecho, en lugar de lesiones clínicas profundas, enrojecidas y de fácil sangrado (comunes al agrandamiento gingival inflamatorio), los pacientes con HG incluidos en la presente investigación presentaron una encía aumentada de tamaño, color rosado y sin tendencia al sangrado. Probablemente, los hallazgos clínicos e histológicos de los pacientes aquí reportados sea el resultado de la disminución de la carga bacteriana y las citocinas inflamatorias relacionada con el inicio y desarrollo del agrandamiento gingival previamente descritas por Gong, et al. ${ }^{15}$, después de haber realizado la fase higiénica periodontal en todos los pacientes, una semana antes del procedimiento quirúrgico.

No excluimos que la acumulación de biofilm dental sea responsable de la $\mathrm{HG}$ en pacientes portadores de ortodoncia como ha sido ampliamente demostrado. Sin embargo, estimamos que no es el único factor involucrado. Incluso, estudios clínicos e histológicos han informado de la presencia de $\mathrm{HG}$ en pacientes con ortodoncia que mantenían una excelente higiene bucal y en los que ningún signo clínico de inflamación gingival fue observado ${ }^{16,17}$. Estos hallazgos podrían ser explicados por la presencia de otros factores desencadenantes de la HG en estos pacientes. Entre ellos, la presencia de dosis baja y continua de níquel liberada en el tejido epitelial como resultado de la corrosión de los aparatos de ortodoncia ${ }^{18,19}$, el estrés mecánico, como consecuencia de un tratamiento de larga duración ${ }^{11}$ y cambios hormonales ${ }^{20}$.

En todos los pacientes con HG portadores de ortodoncia, identificamos un engrosamiento del tejido conectivo gingival acompañado de una acumulación significativa de colágeno distribuidos en gruesos haces con diferentes direcciones. En los casos evaluados, las fibras de colágeno (incluidas el colágeno tipo I y III) parecían ascender desde la zona profunda del tejido conectivo hasta la zona adyacente de las papilas epiteliales, permitiendo observar en los alrededores de esta zona un tejido fibroso en lugar de un tejido conectivo laxo que si fue evidente en los individuos sanos. Este estudio demuestra la organización y disposición de las fibras de colágeno mediante técnicas histológicas e inmunohistoquímicas en pacientes con HG portadores de ortodoncia. Hallazgos similares han sido previamente descritos en otros tipos de $\mathrm{HG}$, incluyendo la $\mathrm{HG}$ hereditaria ${ }^{21}$ y la HG por medicamentos ${ }^{22}$.

El mecanismo mediante el cual se produce una acumulación del colágeno en los tejidos gingivales de los pacientes con $\mathrm{HG}$ portadores de ortodoncia es una pregunta abierta. Sin embargo, reportes indicarían un rol preponderante del factor de crecimiento transformante $\beta 1$ (TGF- $\beta 1$ ) como regulador de las actividades celulares en estos pacientes ${ }^{15}$. Resultados preliminares de nuestro equipo (no publicados) apoyan esta hipótesis y ponen en evidencia el incremento de TGF- $\beta 1$ en FGs de pacientes con HG portadores de ortodoncia comparado con FGs de individuos sanos sin aparatología ortodóntica. Estos niveles elevados de TGF- $\beta 1$ han sido reportados en otros tipos de HG como un factor clave en la inducción del aumento en los niveles del factor de crecimiento del tejido conectivo (CTGF) que parece favorecer una mayor producción de colágeno tisular ${ }^{21,23}$. Aunque estos hallazgos deben ser confirmados, consideramos que la acumulación excesiva de colágeno, incluyendo el colágeno de tipo I y tipo III en el tejido conectivo de pacientes con $\mathrm{HG}$ portadores de ortodoncia observados en esta investigación, probablemente sea el resultado de un desequilibrio entre la secreción de colágeno y la disminución aparente de la actividad de degradación de estos, conducida por las metaloproteinasas de la matriz ${ }^{24,25}$.

La limitación de este trabajo investigativo radicó en la presencia de una muestra reducida de pacientes con $\mathrm{HG}$ portadores de tratamiento ortodóntico. Por ello, estos resultados morfológicos preliminares, aunque deben ser tomados con prudencia, constituyen elementos necesarios para comprender y analizar el desarrollo de posibles estrategias terapéuticas. Evidentemente, futuras investigaciones permitirán confrontar los hallazgos presentados aquí y establecer los niveles de expresión génica del colágeno tipo I y colágeno tipo III y compararlos con los niveles de moléculas involucradas en su degradación. Estos resultados, junto a análisis dirigidos a conocer la relación funcional entre los niveles de TGF- $\beta 1$ - CTGF y la actividad mitótica de los FGs, serán de gran utilidad para dilucidar los aspectos fisiopatológicos involucrados en la $\mathrm{HG}$ de pacientes portadores de tratamiento ortodóntico. 


\section{Conclusión}

El almacenamiento de las fibras de colágeno, incluyendo del colágeno tipo I y tipo III, constituyen un hallazgo histológico característico de los tejidos gingivales de pacientes con hipertrofia gingival portadores de ortodoncia. Futuros estudios son necesarios para dilucidar el fenotipo de los fibroblastos gingivales y la probable pérdida homeostática entre la producción y degradación de colágeno en individuos con hipertrofia gingival por ortodoncia.

\section{Agradecimientos}

Al programa Bolívar Gana con Ciencia de la Gobernación de Bolívar, Colombia y a la Fundación Ceiba por el acompañamiento.

\section{Consideraciones éticas}

Todos los participantes aprobaron su participación mediante firma del consentimiento informado. Este estudio contó con la aprobación de comité de ética en investigaciones de la Universidad de Cartagena No. 349902016 y siguió estrictamente los principios $\mathrm{y}$ aspectos éticos contenidos en la última revisión de la declaración de Helsinki y la Resolución 008430 de 1993 del Ministerio de Salud de Colombia.

\section{Conflicto de interés}

Los autores declaran no tener conflicto de interés.

\section{Referencias}

1. Pascu EI, Pisoschi CG, Andrei AM, Munteanu MC, Rauten AM, Scrieciu M, et al. Heterogeneity of collagen secreting cells in gingival fibrosis--an immunohistochemical assessment and a review of the literature. Rom J Morphol Embryol. 2015; 56(1): 49-61.

2. Ramírez-Rámiz A, Brunet-LLobet L, Lahor-Soler E, Miranda-Rius J. On the cellular and molecular mechanisms of drug-induced gingival overgrowth. Open Dent J. 2017; 11: 420-435. doi: http://dx.doi. org/10.2174/1874210601711010420

3. Drăghici EC, CrăiŢoiu Ş, MercuŢ V, Scrieciu M, Popescu SM, Diaconu OA, et al. Local cause of gingival overgrowth. Clinical and histological study. Rom J Morphol Embryol. 2016; 57(2): 427-435.

4. Sharma S, Shahi AK, Prajapati VK, Singh B. Idiopathic gingival fibromatosis with massive gingival overgrowth: A rare case report. J Indian
Soc Periodontol. 2020; 24(4): 379-382. doi: https:// doi.org/10.4103/jisp.jisp_426_19

5. Watson E, Wood RE, Maxymiw WG, Schimmer AD. Prevalence of oral lesions in and dental needs of patients with newly diagnosed acute leukemia. J Am Dent Assoc. 2018; 149(6): 470-480. doi: https:// doi.org/10.1016/j.adaj.2018.01.019

6. Simancas-Escorcia V, Berdal A, Díaz-Caballero A. Caracterización fenotípica del síndrome amelogénesis imperfecta-nefrocalcinosis: una revisión. Duazary. 2019; 16(1): 129. doi: http:// dx.doi.org/10.21676/2389783X.2531

7. Chatzopoulos GS, Koidou VP, Wolff LF. Systematic review of cyclosporin A-induced gingival overgrowth and genetic predisposition. Quintessence Int. 2017; 48(9): 711-724. doi: http:// dx.doi.org/10.3290/j.qi.a38120

8. González-Jaranay M, Téllez L, Roa-López A, Gómez-Moreno G, Moreu G. Periodontal status during pregnancy and postpartum. PLoS ONE. 2017; 12(5): e0178234. doi: http://dx.doi.org/10.1371/ journal.pone. 0178234

9. Gorbunkova A, Pagni G, Brizhak A, Farronato G, Rasperini G. Impact of orthodontic treatment on periodontal tissues: A narrative review of multidisciplinary literature. Int $\mathrm{J}$ Dent. 2016; 2016:4723589. doi: https://oi. org/10.1155/2016/4723589

10. Rodríguez Vásquez AG, Fernández García LK, Valladares Trochez EH. Prevalencia de agrandamiento y retracción gingival en pacientes con tratamiento de ortodoncia. Port Ciencia. 2018; 16; 21-31. doi: https://doi.org/10.5377/ pc.v13i0.5918

11. Pinto AS, Alves LS, Zenkner JE do A, Zanatta FB, Maltz M. Gingival enlargement in orthodontic patients: Effect of treatment duration. Am J Orthod Dentofacial Orthop. 2017; 152(4): 477-482. doi: https://doi.org/10.1016/j.ajodo.2016.10.042

12. Kantarci A, Augustin P, Firatli E, Sheff MC, Hasturk H, Graves DT, etal.Apoptosisin GingivalOvergrowth Tissues. J Dent Res. 2007; 86(9): 888-892. doi: https://doi.org/10.1177/154405910708600916

13. Meng L, Huang M, Ye X, Fan M, Bian Z. Increased expression of collagen prolyl 4-hydroxylases in Chinese patients with hereditary gingival fibromatosis. Arch Oral Biol. 2007; 52(12): 1209-1214. doi: https://doi.org/10.1016/j. archoralbio.2007.07.006

14. Jadhav T, Bhat KM, Bhat GS, Varghese JM. Chronic inflammatory gingival enlargement associated with orthodontic therapy--a case report. J Dent Hyg. 2013; 87(1): 19-23. 
15. Gong Y, Lu J, Ding X. Clinical, microbiologic, and immunologic factors of orthodontic treatmentinduced gingival enlargement. Am J Orthod Dentofacial Orthop. 2011; 140(1): 58-64. doi: https://doi.org/10.1016/j.ajodo.2010.02.033

16. Zachrisson S, Zachrisson BU. Gingival condition associated with orthodontic treatment. Angle Orthod. 1972; 42(1): 26-34. doi: https://doi. org/10.1043/0003-3219(1972)042<0026:GCAWO $\mathrm{T}>2.0 . \mathrm{CO} ; 2$

17. Şurlin P, Rauten AM, Pirici D, Oprea B, Mogoantă L, Camen A. Collagen IV and MMP-9 expression in hypertrophic gingiva during orthodontic treatment. Rom J Morphol Embryol. 2012; 53(1): 161-165.

18. Gursoy UK, Sokucu O, Uitto V-J, Aydin A, Demirer $\mathrm{S}$, Toker $\mathrm{H}$, et al. The role of nickel accumulation and epithelial cell proliferation in orthodontic treatmentinduced gingival overgrowth. Eur J Orthod. 2007; 29(6): 555-558. doi: https://doi.org/10.1093/ejo/ cjm074

19. Kapadia JM, Agarwal AR, Mishra S, Joneja P, Yusuf AS, Choudhary DS. Cytotoxic and genotoxic effect on the buccal mucosa cells of patients undergoing fixed orthodontic treatment. J Contemp Dent Pract. 2018; 19(11): 1358-1362.

20. Hosadurga R, Nabeel Althaf M, Hegde S, Rajesh $\mathrm{K}$, Arun Kumar M. Influence of sex hormone levels on gingival enlargement in adolescent patients undergoing fixed orthodontic therapy: A pilot study. Contemp Clin Dent. 2016; 7(4): 506. doi: https:// doi.org/10.4103/0976-237X.194099

21. Gawron K, Ochała-Kłos A, Nowakowska Z, Bereta G, Łazarz-Bartyzel K, Grabiec AM, et al. TIMP-1 association with collagen type I overproduction in hereditary gingival fibromatosis. Oral Dis. 2018; 24(8): 1581-1590. doi: https://doi.org/10.1111/ odi. 12938

22. Dannewitz B, Tomakidi P, Syagailo Y, Kohl A, Staehle HJ, Eickholz P, et al. Elevation of collagen type I in fibroblast-keratinocyte cocultures emphasizes the decisive role of fibroblasts in the manifestation of the phenotype of cyclosporin A-induced gingival overgrowth. J Periodont Res. 2009; 44(1): 62-72. doi: https://doi.org/10.1111/ j.1600-0765.2007.01066.x

23. Chen JT, Wang CY, Chen MH. Curcumin inhibits TGF- $\beta 1$-induced connective tissue growth factor expression through the interruption of Smad2 signaling in human gingival fibroblasts. J Formos Med Assoc. 2018; 117(12): 1115-1123. doi: https:// doi.org/10.1016/j.jfma.2017.12.014
24. Martelli-Junior H, Cotrim P, Graner E, Sauk JJ, Coletta RD. Effect of transforming growth factorbeta1, interleukin-6, and interferon-gamma on the expression of type I collagen, heat shock protein 47, matrix metalloproteinase (MMP)-1 and MMP-2 by fibroblasts from normal gingiva and hereditary gingival fibromatosis. J Periodontol. 2003; 74(3): 296-306. doi: https://doi.org/10.1902/ jop.2003.74.3.296

25. Kang CM, Lee JH, Jeon M, Song JS, Kim SO. The Effect of MMP-13, MMP-12, and AMBN on gingival enlargement and root deformation in a new type of gingival fibromatosis. J Clin Pediatr Dent. 2018; 42(1): 50-54. doi: https://doi.org/10.17796/10534628-42.1.9 